the researcher in an accessible format. A podcast interview can help students generate their own questions about course material and better relate to the goals that drive research. Clips also can be played in class to stimulate discussion.

For those considering starting a podcast, you should think about audio quality. Our biggest initial challenge was that the app for recording phone calls often did not produce audio that made it easy to decipher what interviewees said. Various audio reengineering strategies created other problems. We solved the issue by moving to online recording using Zencastr, an inexpensive service. It starts a Voice Over IP call between me and the guest but also locally records the guest's audio for uploading as a .wav file at the end of the call.

Podcasters also should consider filling audience niches. In addition to The Science of Politics, I am involved in the State of the State podcast. Associated with the Institute for Public Policy and Social Research at Michigan State University, it covers state public-policy issues in Michigan with research-informed commentary. It is even more highly targeted to those interested in detailed discussions of politics and policy in one state; however, the format easily could be replicated at other universities. We invite faculty guests to talk about their research and the major issues being discussed in the legislature. We record the episodes, mostly unedited, in a studio on campus in cooperation with the local National Public Radio affiliate. Clips from the podcast also can be heard on a Detroit radio station as part of a university hour. Partnering with a studio and interviewing local guests improves audio quality.

The flowering of the political science podcasting community is an exciting development for the discipline. From a teaching tool to an outreach opportunity, scholars should welcome podcasting as an important outlet for research communication. -

\section{A FEW REASONABLE WORDS}

Casey B. K. Dominguez ${ }^{\mathbb{D}}$, University of San Diego

Cory Charles Gooding D, University of San Diego

Timothy W. McCarty, University of San Diego

\section{DOI:10.1017/S1049096519001665}

Our podcast, A Few Reasonable Words, offers listeners a political science perspective on current events in US politics. Through generous support from the University of San Diego, we have been podcasting since 2016 on a wide range of topics, including immigration policy, US identity, the unitary executive, government shutdowns, voting, and various types of political reforms.

\section{How Do We Use Our Different Perspectives to Find Interesting Ways to Talk about Current Events?}

We are all at least part Americanist, so we usually begin with current events in American politics. We do not have a daily podcast (our frequency varies between weekly and monthly), so we tend to step back from the news cycle while still having a conversation that people find relevant for understanding the current moment.

We also have different specialties: Tim is a political theorist, Cory is a racial and ethnic politics scholar, and Casey studies elections and the presidency. This helps us to have discussions that hit historical and cultural points that three people in the same subfield might not be able to have. (Plato comes up so often that we have a running gag about him.) We did a four-part series on immigration politics in 2018 that was a great example of conversations across subdisciplines.

\section{Why Do We Want to Talk to an Audience in This Format?}

Our primary reason for podcasting is that it allows us to extend the reach of our teaching. We are all active scholars, but teaching is our vocation, and we feel like podcasting is another outlet for sharing what we know with the public. As political scientists, we are frequently frustrated by the "shiny objects" and points of emphasis that capture the attention of the media and, as a result, the public. This reality challenged us to think about how we could offer the public an alternative resource in a way that is accessible and informative. Like other political scientists who are blogging and writing op-eds, we seek to fill the void that the current media leaves open in terms of providing context for the maelstrom of current events.

We have continued the podcast into our third year for two additional reasons. First, it is fun for us. The fact that we enjoy our conversations makes them more fun to listen to and a worthwhile way for us to challenge and refine our individual perspectives on political events and trends.

Second, whereas there is no immediate professional benefit to podcasting, there also is no penalty. Our department and our university value public service as part of the tenure and promotion process. If we received signals that the time we spend on the podcast would be held against us, we probably would not continue. That said, we do have to balance podcasting against other demands on our time, which creates variability in how often we post new episodes.

\section{How Do We Think about and Try to Reach Our Audience?}

Our audience is different from podcasts aimed at true specialists (e.g., New Books in Political Science), journalists, and policy makers. We want to speak to regular folks, much like we do in our classes.

We know that we have fans among our current and former students, but we also know that our listenership extends far beyond this group. Our feedback comes in the form of occasional emails about specific episodes. Based on the questions and comments we receive, we imagine our audience to be people who follow politics closely, who perhaps once took classes in political science and miss it. We try to engage with current events at that informed, general-interest level.

None of us are experts in reaching a mass-market audience. We have not systematically analyzed the demographic, ideological, or partisan profile of our audience, other than reviewing the number of downloads. (We are happy knowing that, in total, our podcast episodes have been downloaded tens of thousands of times.) To reach beyond our personal and student networks, we rely on our social media circles and our university's public relations department. They have helped us get spotlights on our local public radio station and in our university's magazine. We saw a small but measurable uptick in downloads after the public radio spotlight in particular, and we received emails after the magazine spotlight.

\section{What Are Our Hopes for the Podcast?}

Obviously, we would love to be an inspiration for the US political media and have political science replace punditry, but no 
one is holding their breath for that. In the absence of a complete transformation of the political media, we like to think that our podcast can make accessible some political science insights to audiences that are not sitting in our classrooms and reading journals like this one. Ideally, the podcast provides not only specific information and insights to our listeners but also serves as an exemplary model of the types of conversations that are possible when people decide to look at politics through a political science lens.

\section{POLITICAL SCIENCE, PUBLIC INTELLECTUALISM, AND} PODCASTING

\author{
Philip W. Barker, Keene State College \\ Suzanne M. Chod, North Central College \\ William J. Muck ${ }^{\circledR}$, North Central College
}

\section{DOI:10.1017/S104909651900163X}

Our experience in podcasting has had a profound impact leaving us convinced that there is much to be gained for the field of political science and for political scientists in particular. We launched our podcast, Barstool Politics, in the fall of 2016 during the final months of the presidential campaign. Our goal was to offer insight and reflection on the dramatic social and political upheaval taking place. We watched as our political system was catapulted into a fundamentally new era, and it felt as if the field of political science had been left on the sidelines. Essentially, we had ceded the role of "public intellectual" to pundits and others who may not have the same academically based understanding of political institutions, behaviors, and policy outcomes. We thought podcasting, in a small way, could help to fill that gap. Since then, we have realized the tremendous potential that podcasting can offer political scientists as a medium to provide evidence-based and theoretically grounded analysis to a broader nonacademic audience. In particular, political scientists can take the empirical and theoretical knowledge that our field has generated and use it to make sense of day-to-day political developments. This is, in essence, exactly what we do as teachers in the classroom: we take complex research and make it accessible to our students. Podcasting simply expands our reach to a wider audience. the insights of our field to the general public. As a result, we often find ourselves touching on relevant political science literature as a way to provide context and structure to a current political issue. For instance, in 2019, we discussed President Trump's difficulty in passing his legislative agenda through Congress by referencing Skowronek's (2011) concept of disjunctive presidencies. Utilizing this framework makes sense of a fragmented Republican Party and allows us to think about what might be next for American politics. In another episode, we discussed the growing elements of isolationism in contemporary US foreign policy. We found ourselves turning to Roskin's (1974) "generational paradigms" as a way to talk about gradual shifts in US policy in response to previous failures in interventionism. More recently, we referenced hegemonic stability theory to provide perspectives on growing economic tensions with China and Just War Doctrine to explain political violence in Game of Thrones. These references to the literature generally are not preplanned but rather arise organically and conversationally. We try to avoid anything that feels like a typical lecture, instead attempting to show how our field is useful, illuminating, and approachable. In addition, we regularly feature disciplinary subfield experts to push past overly simplistic partisan interpretations and to provide deeper context about political campaigns, election results, foreign policy, and Supreme Court decisions. In our perspective, this is markedly different from the approach that a pundit might take. Our purpose is not to argue for argument's sake but instead to wrestle with and better understand the key issues and dilemmas in the world today. Our listeners provide regular feedback noting how the podcast has helped them to appreciate the complexity of a political question and to move past conventional partisan explanations.

At a deeper level, we believe podcasting can help political scientists deliver on one of their core responsibilities: civic education. In Robert Putnam's 2003 presidential address to the American Political Science Association, he argued that political science has two mutually important and reinforcing obligations: "attending to the concerns of our fellow citizens" and "pursuit of scientific truth" (Putnam 2003, 250). He did not argue that we are "philosopher-kings" or even problem solvers but rather experts who have a responsibility to "shed light" on public problems (Putnam 2003, 252). In 2011, Smith noted that our discipline has failed to become more relevant since Putnam's call to action. $\mathrm{He}$ argued for political science research to be "presented in ways that

\section{Essentially, we had ceded the role of "public intellectual" to pundits and others who may not have the same academically based understanding of political institutions, behaviors, and policy outcomes.}

We broadcast weekly, organizing each episode around the major political developments of the week. Prior to taping, we review what we perceive as the most important news stories and then develop an outline with introductory comments for each topic. The podcast is divided into two segments. We open with a deep dive into one topic for 30 minutes of discussion. The second half of the episode follows a "speed-round" format in which we briefly examine five additional topics for roughly five minutes each. Our intent is to offer a fun, lively, and engaging podcast that bridges the gap between punditry and political science by bringing at least have the potential to be understood, assessed, and perhaps even utilized productively in the public sphere" (Smith 2011, 17). This debate continues: Desch (2019) outlined the push-pull between rigor and relevance in the Chronicle of Higher Education, defining relevance as "whether scholarship contributes to the making of policy decisions." Although certainly important, we do not believe that peer-reviewed publications directed at policy makers should be the only measuring stick for relevance. As we all know, political scientists are not regularly contacted by practitioners, public officials, or the media. This is a loss for the public because our 